\title{
Comparing the Effectiveness of Carvedilol and Propranolol to Prevent Reoccurrence of Esophageal Variceal Bleeding in Patients with Liver Cirrhosis.
}

\author{
LIAQAT KHURSHID ${ }^{1}$, ASADULLAH KHAN², SALIM HASSAN ${ }^{3}$, ADIL NASEER KHAN $^{4}$ \\ ${ }^{1}$ Consultant Gastroenterologist \& Hepatologist, Ayub Teaching Hospital Abbottabad \\ ${ }^{2}$ Consultant Gastroenterologist and Hepatologist, Department of Gastroenterology and Hepatology, Ayub Teaching Hospital Abbottabad \\ ${ }^{3} \mathrm{MO}$ TBC Unit, DHO Office, Parachinar \\ ${ }^{4}$ Prof and Head of Department of Gastroenterology and Hepatology, Ayub Teaching Hospital, Abbottabad \\ Corresponding Author: Dr. Liaqat Khurshid, Email: drliaqatkhurshid@gmail.com
}

\begin{abstract}
Objective: To compare the efficacy of carvedilol and propranolol to prevent reoccurrence of esophageal variceal bleeding in patients with liver cirrhosis.

Study Design:

Place and Duration: Department of Gastroenterology and Hepatology, Ayub Teaching Hospital, Abbottabad, Pakistan for six months duration from 15

Methods: Total one hundred and forty patients of ages between 18-65 years were presented in this study. Patients detailed demographics age, sex, body mass index and Child-Turcotte-Pugh (CTP) class were recorded after taking written informed consent. Patients were equally $(n=70)$ divided into two groups. Group A had 70 patients and received carvedilol while group $B$ had 70 patients and received propranolol for 6 months. Reoccurrence ofesophageal variceal bleeding in cirrhotic patients among both groups were observed at $2^{\text {nd }}, 4^{\text {th }}$ and $6^{\text {th }}$ months and patients pulse rate, arterial pressure and portal vein flow were recorded at these time points. Complete data was analyzed by SPSS 26.0 version.

Results: Mean age of the patients in group A was $40.38 \pm 5.87$ years with mean BMl $28.09 \pm 7.33 \mathrm{~kg} / \mathrm{m}^{2}$ and in group B mean age was $39.43 \pm 12.69$ years with mean BMl $27.53 \pm 8.84 \mathrm{~kg} / \mathrm{m}^{2}$. In group A $45(64.3 \%)$ patients were males and $25(35.7 \%)$ were female patients while in group B $50(71.43 \%)$ were male patients and 20 $(28.7 \%)$ patients were females. We found that there was no statistically significant difference observed among both groups regarding these demographic variables. Reoccurrence of bleeding observed in group A was significantly lower (among $20(28.6 \%)$ cases) as compared to group B (among $36(51.43 \%)$ cases). Pulse rate, mean arterial pressure and portal vein flow was found lower in the carvedilol group as compared to propanol group with $p$ value $<0.05$ upon follow up at2,4 and 6 months.

Conclusion: We found in this study that the drug carvedilol was more effective and safe to prevent reoccurrence of esophageal variceal bleeding in cirrhotic patients as compared to propanol.

Keywords: Cirrhotic patients, Carvedilol, Propanol, Portal vein flow, Mean arterial pressure
\end{abstract}

\section{INTRODUCTION}

Liver cirrhosis is still the world's 12th biggest cause of mortality and is inevitably accompanied by portal hypertension, which is responsible for most of the disease's consequences, including variceal hemorrhage, ascites, and hepatic encephalopathy [1]. As the name suggests, portal hypertension is characterized by a pathologic increase in the portal pressure gradient (the pressure difference between the portal and hepatic veins) of greater than 5 $\mathrm{mmHg}$. Reducing portal pressure improves clinical outcomes and minimizes recurrent bleeding, ascites, encephalopathy and death [3-5].

More than three decades have passed since betaadrenergic receptor antagonists (beta-blockers) were first approved for use in the treatment of portal hypertension. Since 1980, when Lebrec et al published the first report on their function in portal hypertension [6], non-selective beta blockers (NSBB) have been frequently used. Portal hypertension invariably accompanies liver cirrhosis and develops even before the onset of liver cirrhosis. It is caused by the following factors:1) Structural changes in the liver (fibrous tissue, vascular distortion from regenerative nodules, and micro thrombi) leading to increased intrahepatic resistance to portal blood flow (7). Increased hepatic vascular resistance with resultant increased intrahepatic resistance to portal blood flow due to endothelial dysfunction mainly from reduced nitric oxide (NO) availability [8]. Splanchnic vasodilation secondary to increased splanchnic NO production which leads to increased blood flow to the gut and into portal venous system [9]. Systemic vasodilation which by causing a drop in mean arterial pressure triggers reflex neurohumoral and vasoconstrictive arcs and lead in turn to a hyperdynamic circulatory state from sodium and water retention, increased blood volume and increased cardia output. Among the initial consequences of portal hypertension is the formation of portosystemic collaterals. These collaterals form at various locations but the most clinically relevant are the ones that develop through the coronary and /or short gastric veins resulting in the formation of gastroesophageal varices [9]. Although the development of these collaterals should reduce portal pressure by shunting blood away from portal venous system into systemic circulation, the concomitant splanchnic vasodilation occurring as part of pathophysiology of portal hypertension prevents this and therefore portal hypertension persists despite the development of portosystemic collaterals [10] 
Non-selective beta-blockers (NSBB) without alpha-1 adrenergic receptor blocking effect, like propranolol and nadolol, reduce portal pressure by blocking beta adrenergic receptors. Beta-1 blockade decreases portal flow by decreasing cardiac output (minor effect) and Beta-2 blockade reduces portal flow by decreasing splanchnic vasodilation (major effect) [11]. Carvedilol, a NSBB with anti-alpha 1 adrenergic activity, in addition to acting as a NSBB to decrease portal pressure also act as vasodilator of intrahepatic circulation (due to its anti-alpha 1 adrenergic activity). Although Carvedilol has been found to be associated with a greater decrease in HVPG (portal pressure) when compared with propranolol or nadolol, is also associated with a greater decrease in mean arterial pressure (MAP) because its vasodilatory effect is not limited to intrahepatic vasculature alone [12].

There are several NSBBs that have been used clinically in individuals with cirrhosis, such as propranolol, nadolol, timolol, atenolol, metoprolol, and carvedilol. For treating portal hypertension, propranolol was the first and most well investigated NSBB. As a nonselective betablocker with anti-alpha 1 adrenergic action, carvedilol can be used for portal hypertension. Thisis a relatively new area of application for NSBB therapy and has shown good clinical outcomes.

The nonselective beta-receptor blocker carvedilolwith its anti-alpha 1 adrenergicactivityhas been shown to be 2-4 times more powerful than propranolol in trials done to investigate its efficacy for heart failure [13]. In our study we compared Carvedilol and propranolol to see if carvedilol was more effective than propranolol in patients with cirrhosis in preventing re-occurrence of bleeding.

\section{MATERIAL AND METHODS}

This study was conducted at The Department of Gastroenterology and Hepatology, Ayub Teaching Hospital, Abbottabad, Pakistanfor six months duration from $15^{\text {th }}$ November 2020 to $15^{\text {th }}$ May 2021 and comprised of 140 patients. Patients detailed demographics age, sex, BMI and CTP class were recorded after taking written informed consent. Those patients who did not agree were excluded from this study.

Cirrhotic patients within the age group 18-65 years who presented with acute upper gastrointestinal bleeding (hematemesis and/or melena) were enrolled in this study. They were treated with somato statin analog (octreotide or terlipressin) and resuscitated. Endoscopy of the upper gastrointestinal tract was performed within 12 to 24 hours of admission to confirm the presence of esophageal variceal hemorrhage as the cause of their acute upper gastrointestinal bleeding and endoscopic variceal ligation (EVL) was performed. Those patients in which the cause of bleeding was determined to be other than esophageal varices were excluded from the study. Patients were equally $(n=70)$ divided into two groups. Group A had 70 patients and received carvedilol while group $B$ had 70 patients and received propranolol for 6 months as secondary prophylaxis for esophageal variceal hemorrhage.

For secondary prophylaxis, the dose of propranolol used ranged from $20 \mathrm{mg}$ twice daily to a maximum of 160 $\mathrm{mg}$ per day and the dose of carvedilol used ranged from6.25mg once daily to $6.25 \mathrm{mg}$ twice daily. Therapy goals were to bring resting heart rate to $55-60$ beats per minute (bpm) and systolic blood pressure should not decrease to $<90 \mathrm{mmHg}$. Drugs were discontinued in any patient who developed intolerance to beta blockers before or after attainment of therapy goals. Reoccurrence of bleeding in cirrhotic patients among both groups was observed at $2^{\text {nd }}, 4^{\text {th }}$ and $6^{\text {th }}$ months at which point pulse rate, arterial pressure and portal vein flow were also recorded. Complete data was analyzed by SPSS 26.0 version.

\section{RESULTS}

Mean age of the patients in group $A$ was $40.38 \pm 5.87$ years with mean BMl $28.09 \pm 7.33 \mathrm{~kg} / \mathrm{m}^{2}$ and in group $B$ mean age was $39.43 \pm 12.69$ years with mean BMI $27.53 \pm$ $8.84 \mathrm{~kg} / \mathrm{m}^{2}$. In group A 45 (64.3\%) patients were males and $25(35.7 \%)$ were female patients while in group B 50 $(71.43 \%)$ were male patients and $20(28.7 \%)$ patients were females. There was no statistically significant difference observed among both groups regarding these demographic variables. Also no statistically significant difference was observed among the Child Turcotte Pugh (CTP) class of the patients in the study groups. (table 1)

Table 1: Baseline detailed characteristics of enrolled cases

\begin{tabular}{|l|l|l|l|}
\hline Variables & Group A & Group B & Total \\
\hline Mean age (years) & $40.38 \pm 5.87$ & $39.43 \pm 12.69$ & \\
\hline Mean BMl & $28.09 \pm 7.33$ & $27.53 \pm 8.84$ & \\
\hline Gender & & & \\
\hline Male & $45(64.3 \%)$ & $50(71.43 \%)$ & $95(67.9 \%)$ \\
\hline Female & $25(35.7 \%)$ & $20(28.7 \%)$ & $45(32.1 \%)$ \\
\hline Child Turcotte Pugh & & & \\
\hline Class A & $8(11.43 \%)$ & $8(11.43 \%)$ & $16(11.43 \%)$ \\
\hline Class B & $22(31.43 \%)$ & $23(32.9 \%)$ & $45(32.14 \%)$ \\
\hline Class C & $40(57.14 \%)$ & $39(55.7 \%)$ & $79(56.43 \%)$ \\
\hline
\end{tabular}

Reoccurrence of bleeding observed in group $A$ was significantly lower, 20 patients $(28.6 \%)$ as compared to group $B$ in which re-occurrence of bleeding was observed in $36(51.43 \%)$ patients. Pulse rate, mean arterial pressure and portal vein flow was found lower in the carvedilol group as compared to propanol group with $p$ value $<0.05$ after follow-up at 2,4 and 6 months. (table 2)

Table 2: Comparison of re-occurrence bleeding among both groups

\begin{tabular}{|c|c|c|c|}
\hline Variables & Group A & Group B & $P$ value \\
\hline $\begin{array}{l}\text { Reoccurrence } \\
\text { of bleeding }\end{array}$ & $20(28.6 \%)$ & $36(51.43 \%)$ & 0.05 \\
\hline 2 months & $4(5.7 \%)$ & $6(8.6)$ & 0.65 \\
\hline 4 months & $10(14.3 \%)$ & $14(22.9 \%)$ & 0.98 \\
\hline 6 months & $6(8.6 \%)$ & $16(21.11)$ & 0.08 \\
\hline \multicolumn{4}{|c|}{ Decrease in MAP $(\mathrm{mmHg})$} \\
\hline 2 months & $-8.61 \pm 0.4$ & $-8.61 \pm 0.44$ & 0.84 \\
\hline 4 months & $-10.39 \pm 0.98$ & $-7.11 \pm 0.58$ & 0.03 \\
\hline 6 months & $-14.12 \pm 6.11$ & $-9.54 \pm 0.35$ & 0.02 \\
\hline \multicolumn{4}{|l|}{ Heart rate (bpm) } \\
\hline 2 months & $85 \pm 12$ & $85 \pm 23$ & 0.88 \\
\hline 4 months & $73 \pm 16$ & $77 \pm 12$ & 0.04 \\
\hline 6 months & $67 \pm 55$ & $74 \pm 87$ & 0.05 \\
\hline \multicolumn{4}{|c|}{ Portal vein flow (ml/min) } \\
\hline 2 months & $918.111 \pm 112.78$ & $907.65 \pm 132.88$ & 0.92 \\
\hline 4 months & $732.32 \pm 76.34$ & $811.12 \pm 121.09$ & 0.05 \\
\hline 6 months & $596.32 \pm 55.12$ & $670.23 \pm 131.44$ & 0.03 \\
\hline
\end{tabular}

\section{DISCUSSION}

Carvedilol was discovered to have a beneficial effect on reoccurrence of esophageal variceal bleeding in patients 
with liver cirrhosis during the study which is one of the most devastating outcomes of liver cirrhosis with resultant portal hypertension. However, carvedilol is used less frequently than propranolol for secondary prevention of variceal hemorrhage in patients with portal hypertension due to liver cirrhosis.

In our study a total of 140 patients were enrolled. Frequency of males $95(67.9 \%)$ were greater than that of females $45(32.1 \%)$. Mean age of the patients in group $A$ was $40.38 \pm 5.87$ years with mean BMl $28.09 \pm 7.33 \mathrm{~kg} / \mathrm{m}^{2}$ and in group B mean age was $39.43 \pm 12.69$ years with mean BMI $27.53 \pm 8.84 \mathrm{~kg} / \mathrm{m}^{2}$. We found that there was no statistically significant difference among two groups with regard to age, gender and $\mathrm{BMI}[14,15]$. According to the research, carvedilol prevented esophageal variceal hemorrhage, liver decompensation, and mortality in 50 percent of non-responders to propranolol. [16] In spite of the fact that carvedilol is less extensively utilized in secondary prophylaxis, it has a stronger therapeutic potential by not only reducing the portal blood flow but also decreasing the intrahepatic vascular resistance. Because of this carvedilol was found beneficial for the secondary prevention of variceal bleeding in patients with portal hypertension $[17,18]$.

In our study, reoccurrence of bleeding observed in group A was significantly lower (20 (28.6\%) cases) as compared to group B (36 (51.43\%) patients). Pulse rate, mean arterial pressure and portal vein flow was found lower in the carvedilol group as compared to the propranolol group with $p$ value $<0.05$ after follow up at 2,4 and 6 months. Different previous studies presented findings similar to our study. [19-20].

Propranolol rebleeding was observed in 25 out of 69 patients (36 percent) in a research by Faust Feu and colleagues [21]. Between the two groups, the need for temporary drug abstinence for a few days was comparable. A retrospective analysis of 264 patients with decompensated cirrhosis and carvedilol use found that the carvedilol group had a 24 percent higher survival rate than the non-carvedilol group ( $p$ 0.0001). This group's long-term survival was significantly higher than that of the noncarvedilol group ( $p$ 0.001), and the difference was statistically significant [22].

According to this systematic study, carvedilol appeared to be more effective than propranolol in preventing reoccurrence of esophageal variceal bleeding in patients with cirrhosis.

\section{CONCLUSION}

Based on our observation in this study we conclude that the drug carvedilol when used for secondary prophylaxis to prevent re-occurrence of bleeding from esophageal varices in cirrhotic patients is more effective than the drug propanol.

However, we admit certain limitations of our study including small sample size and limited duration of patient follow up.Moreover, we did not study the effectiveness of carvedilol vs propranolol based on size of esophageal varices which needs further research.

\section{REFERENCES}

1. Lozano R, Naghavi M, Foreman K, Lim S, Shibuya K, Aboyans V, Abraham J, Adair T, Aggarwal R, Ahn SY, et al. Global and regional mortality from 235 causes of death for 20 age groups in 1990 and 2010: a systematic analysis for the Global Burden of Disease Study 2010. Lancet. 2012;380:2095-2128.

2. de Franchis R. Revising consensus in portal hypertension: report of the Baveno $\mathrm{V}$ consensus workshop on methodology of diagnosis and therapy in portal hypertension. J Hepatol. 2010;53:762-768.

3. Feu F, Bordas JM, Luca A, García-Pagán JC, Escorsell A, Bosch J, Rodés J. Reduction of variceal pressure by propranolol: comparison of the effects on portal pressure and azygos blood flow in patients with cirrhosis. Hepatology. 1993;18:1082-1089.

4. Abraldes JG, Tarantino I, Turnes J, Garcia-Pagan JC, Rodés J, Bosch J. Hemodynamic response to pharmacological treatment of portal hypertension and long-term prognosis of cirrhosis. Hepatology. 2003;37:902-908.

5. D'Amico G, Garcia-Pagan JC, Luca A, Bosch J. Hepatic vein pressure gradient reduction and prevention of variceal bleeding in cirrhosis: a systematic review. Gastroenterology. 2006;131:16111624.

6. Lebrec D, Nouel O, Corbic M, Benhamou JP. Propranolol--a medical treatment for portal hypertension? Lancet. 1980;2:180-182.

7. Bosch J, Groszmann RJ, Shah VH. Evolution in the understanding of the pathophysiological basis of portal hypertension: how changes in paradigm are leading to successful new treatments. J Hepatol 2015;62(1 Suppl):S121-S130.

8. Iwakiri Y, Groszmann RJ. Vascular endothelial dysfunction in cirrhosis. J Hepatol 2007;46:927-934.

9. Fernandez M, Vizzutti F, Garcia-Pagan JC, Rodes J, Bosch J. AntiVEGF receptor-2 monoclonal antibody prevents portalsystemic collateral vessel formation in portal hypertensive mice. Gastroenterology 2004;126:886-894.

10. Sikuler E, Kravetz D, Groszmann RJ. Evolution of portal hypertension and mechanisms involved in its maintenance in a rat model. Am J Physiol 1985;248:G618-G625.

11. Kroeger RJ, Groszmann RJ. Effect of selective blockade of beta-2 adrenergic receptors on portal and systemic hemodynamics in a portal hypertensive rat model. Gastroenterology 1985; 88:896-900.

12. Sinagra E, Perricone G, D'Amico M, Tine F, D'Amico G. Systematic review with meta-analysis: the haemodynamic effects of carvedilol compared with propranolol for portal hypertension in cirrhosis. Aliment Pharmacol Ther 2014;39:557-568.

13. Frishman WH. Carvedilol. N Engl J Med. 1998;339:1759-1765.

14. Abid S, Ali S, Baig MA, Waheed AA. Is it time to replace propranolol with carvedilol for portal hypertension?. World J GastrointestEndosc. 2015;7(5):532-539. doi:10.4253/wjge.v7.i5.532

15. Rodrigues SG, Mendoza YP, Bosch J. Beta-blockers in cirrhosis: Evidence-based indications and limitations. JHEP Rep. 2019;2(1):100063. Published 2019 Dec 20.

16. Reiberger T, Ulbrich G, Ferlitsch A, Payer B A, Trauner M, et al. (2013) Carvedilol for primary prophylaxis of variceal bleeding in cirrhotic patients with hemodynamic non-response to propranolol. Gut 62(11): 1634-1641.

17. Leithead J.A., Rajoriya N., Tehami N., Hodson J., Gunson B.K. Tripathi D. Non-selective beta-blockers are associated with improved survival in patients with ascites listed for liver transplantation. Gut. 2015;64(7):1111-1119.

18. Hamal AB, KC S, Thapa P, Sharma D, Karki N, et al. Carvedilol Versus Propranololol for Secondary Prophylaxis of Variceal Hemorrhage in Patients with Liver Cirrhosis. Adv Res GastroenteroHepatol, 2020;15(4): 555920.

19. Kim SG, Kim TY, Sohn JH, Um SH, Seo YS, Baik SK, Kim MY, Jang JY, Jeong SW, Lee B, Kim YS, Suk KT, Kim DJ. A, randomized, multi-center, open-label study to evaluate the efficacy of carvedilol vs. propranolol to reduce portal pressure in patients with liver cirrhosis. Am J Gastroenterol. 2016;111(11):1582-9.

20. Steib, C.J., Gerbes, A.L. Secondary prophylaxis for variceal bleeding: carvedilol vs. propranolol. Hepatollnt 11, 141-142 (2017).

21. Feu F, Garcia Pagan J C, Bosch J, Luca A, Escorsell A et al. (2005) Relation between portal pressure response to pharmacotherapy and risk of recurrent variceal hemorrhage in patients with cirrhosis. The Lancet 346(8982): 1056-1059.

22. Sinha R., Lockman K.A., Mallawaarachchi N., Robertson M., Plevris J.N., Hayes P.C. Carvedilol use is associated with improved survival in patients with liver cirrhosis and ascites. J Hepatol. 2017;67(1):4046. 